\title{
Equilibrium sorption of crude oil by expanded perlite using different adsorption isotherms at $298.15 \mathrm{k}$
}

\author{
${ }^{1 * A}$ Alihosseini; ${ }^{2}$ V. Taghikhani; ${ }^{2}$ A. A. Safekordi; ${ }^{2}$ D. Bastani \\ ${ }^{1}$ Department of Chemistry, Islamic Azad University, Ilam Branch, Ilam, Iran \\ ${ }^{2}$ Department of Chemical and petroleum Engineering, Sharif University of Technology, Tehran, Iran \\ Received 24 October 2009; $\quad$ revised 5 January 2010; accepted 28 April 2010; availaEOHonline 1 June 2010
}

\begin{abstract}
During the past decades, a significant increase occurred in accidental oil spill in the aquatic environments. In this regard, oil spill in Marine freshwater is still considered as a major environmental hazard. In this research, the experimental data on the sorption capacity of expanded perlite to crude oil were correlated with the equilibrium isotherm of Langmuir, Freudlich, Tempkin and the three parameter Redlich-Peterson isotherms. The results obtained from each specified isotherms were compared and accuracy of the models were favorably discussed. Accuracy of each model using the error function were evaluated. Moreover, the effect of type of objective function on the final results was investigated. To bring up the idea; the sum of square of the average squares of the errors, the sum of the squares of the errors, the hybrid fractional error function, Marquardt's percent standard deviation and Chi-Square objective function were used and the accuracy was obtained using each objective function. The results showed that the RedlichPeterson model can better represent the equilibrium isotherm data for the crude oil to be up taken on the expanded perlite.
\end{abstract}

Keywords: Adsorption isotherms; Crude oil; Expanded perlite; Sorption capacity

\section{INTRODUCTION}

Sorption techniques widely assists in high-quality treated effluents. For this reason, sorption process has been investigated as a method of removing crude oil from seawater (Riazi and Al-Enezi, 1999; Yuh et al., 2005; Abdel-Ghani et al., 2009). Exfoliated graphite (Kawahara et al., 2002) and activated carbon (Yoko et al., 2002; Chen et al., 2010) are high effective for the removal of spill oil from seawater (Ingaki et al., 2001). However, the use of exfoliated graphite and activated carbon may not be suitable in developing countries because of its high cost. Thus, it is more suitable to use adsorbents such as clay minerals, peat and wood powder (McKay and Ho, 1998; Ghalambor, 1999; Mahvi, 2008).

Among them, clay minerals (Adams et al., 2008) such as perlite has received great deal of attention. Perlite has a low density, high surface area and a low thermal conductivity. Also, since most perlite samples have high silica content (usually greater than $70 \%$ ), they are high privileged with adsorptive characteristics (Dogan et al., 2000). The adsorptive character of perlite

*Corresponding Author Email: afsharalihosseini@yahoo.com Tel./Fax: +982166861155 is due to the silanol groups formed by silicon atoms on the surface of perlite (Acemioglu, 2005). The types of silanol groups are shown as follows:<smiles>C[Si](O)(O)O</smiles><smiles>C[Si](O)(O)O</smiles><smiles>C[Si](O)(O)O</smiles>

Moreover, below the hydrous oxide surface groups in alumina are shown:

$\equiv \mathrm{Al}-\mathrm{OH}$ Or<smiles>O[Al]O</smiles>

The silicone atoms at the surface tend to maintain their tetrahedral coordination with oxygen. They complete their coordination at room temperature by attachment to monovalent hydroxyl groups, forming silanol groups. The surface of perlite becomes more negatively or positively charged according to the $\mathrm{pH}$ of the medium. This situation affects sorption capacity.

Also, expanded perlite is an inert chemical which could be used as excellent filter aid and as filler in various processes and materials (Polatli et al., 2001). 
Moreover, expanded perlite is commonly used in the processing of vegetable fat, juice, beer in food industry. It is also used in cleaning of dams and ponds in aquatic environment, in obtaining of a clear liquid as a filter product, growing of seed and regularizing of the soil in agriculture and in so many other industrial applications. Adsorption has been an effective separation process for a wide variety of applications (Sylwia, et al., 2003; Nameni et al., 2008). The most widely used adsorbent for industrial applications is exfoliated graphite and activated carbon (Malik, 2004; Gueu et al., 2007; Hussein et al., 2008). The analysis of the isotherm data is important to develop an analytic equation which accurately represents the results and could be used for design purposes (Louis et al., 1998; Pandey et al., 2010). The most well-known isotherms applied in solidliquid systems are the theoretical equilibrium isotherms, including Freundlich (Freundlich, 1906; Wu et al., 2001) as the earliest known relationship; Langmuir (Langmuir, 1918) the best known and most often used isotherm for sorption of solute from a liquid solution and Redlichpeterson (Redlich and Peterson, 1959) containing three parameters isotherms. In addition, the latter is an equation comprised of Freundlich and Langmuir isotherms and Tempkin (Tempkin and Pyzhev, 1940) isotherm which represents data equilibrium of adsorption.

Linear regression and least square method were frequently used to determine the most fitted model throughout the years and finding the parameters of the models, respectively. However, transformations of non-linear isotherm equations to linear form implicitly alter their error structure and may also violate the error variance and normality assumption of standard least squares. In this study, a comparison of linear regression and five different error functions as: a) the sum of square of the average squares of the errors (ERAV). b) The sum of the squares of the errors (ERRSQ). C) The hybrid fractional error function (HYBRID). d) Marquardt's percent standard deviation (MPSD). e) Chi-square analysis $(\chi 2)$ were examined of four isotherms (Langmuir, Freundlich, Redlich-Peterson and Tempkin) and have been applied to the experiment of crud oil sorption on expanded perlite(Marquardt, 1963; Allen et al ., 2003)

In this work, cost-effective expanded perlite samples were selected as a sorbent for the investigation of sorption isotherm of crude oil from oil and seawater mixing. Perlite is glass volcanic rock varying in color from gray to black When it is heated to elevated temperatures $\left(850-1100^{\circ} \mathrm{C}\right)$, it expands to 35 times its internal volume and called as 'expanded perlite' (Bastani et al., 2006).

\section{MATERIALS AND METHODS}

The successful representation of the dynamic adsorptive separation of solute from solution onto an adsorbent depends upon a good description of the equilibrium separation between the two phases. Adsorption equilibrium is the amount of solute being adsorbed onto the adsorbent and equal to the amount being desorbed. At this point, the equilibrium solution concentration remains constant. By plotting solid phase concentration against liquid phase concentration graphically, it is possible to depict the equilibrium adsorption isotherm. There are many theories relating to adsorption equilibrium.

\section{Langmuir isotherm}

The Langmuir isotherm theory assumes monolayer coverage of adsorbate over a homogenous adsorbent surface. Graphically, plateau characterizes the Langmuir isotherm. Therefore, at equilibrium, a saturation point is reached where no further adsorption can occur. Sorption is assumed to take place at that site. In Eq. 2, $\mathrm{K}_{\mathrm{L}}$ and $\mathrm{a}_{\mathrm{L}}$ are the Langmuir isotherm constants while $\mathrm{C}_{\mathrm{e}}$ is the oil weight in the liquid phase and $\mathrm{q}_{e}$ is the oil weight in the solid phase at equilibrium state.

$$
q_{e}=\frac{K_{L} C_{e}}{1+a_{L} C_{e}}
$$

The Langmuir constant, $\mathrm{K}_{\mathrm{L}}$ and $\mathrm{a}_{\mathrm{L}}$ are evaluated of the linearization of Eq. 2. The linear expression takes the following form:

$$
\frac{C_{e}}{q_{e}}=\frac{1}{K_{L}}+\frac{a_{L} C_{e}}{K_{L}}
$$

Hence, by plotting $\mathrm{C}_{\mathrm{e}} / \mathrm{q}_{\mathrm{e}}$ against $\mathrm{C}$, it is possible to obtain the value of $K_{L}$ from the intercept $\left(1 / K_{L}\right)$ and the value of $a_{L}$ from the slope $\left(a_{L} / K_{L}\right)$. The theoretical monolayer capacity is $\mathrm{Q}_{0}$ and is numerically equal to $\left(\mathrm{K}_{\mathrm{L}} / \mathrm{a}_{\mathrm{L}}\right)$. The Langmuir equation is applicable to homogeneous sorption where the sorption of each molecule has equal sorption activation energy. The equation is thermodynamically consistent and follows Henry's Law at low concentrations. Therefore, as $\mathrm{C}_{\mathrm{e}}$ 
becomes lower, $\mathrm{a}_{\mathrm{L}} \mathrm{C}_{\mathrm{e}}$ is much less than unity and $\mathrm{q}_{\mathrm{e}}$, that is, analogous to Henry's Law.

\section{Freundlich isotherm}

The Freundlich expression is an exponential equation and therefore, assumes that as the adsorbate concentration increases with the concentration of adsorbate on the adsorbent surface. Theoretical, using this expression, an infinite amount of adsorption can occur.

$q e=K_{F} C_{e}^{b_{f}}$

In this equation, $\mathrm{K}_{\mathrm{F}}$ and $\mathrm{b}_{\mathrm{f}}$ are the Freundlich constants. This expression is characterized by the heterogeneity factor, $b_{\mathrm{f}}$, and thus the Freundlich isotherm may be used to describe heterogeneous system (Moon and Lee, 1983; Al-Duri and McKay, 1988). The Freundlich equation agrees well with the Langmuir equation over moderate concentration ranges but, unlike the Langmuir expression, it does not reduce to the linear isotherm (Henry's Law) at Low surface coverage. Both these theories suffer from a drawback that equilibrium data over a wide concentration range cannot be fitted with a single set of constants .To determine the constant $\mathrm{K}_{\mathrm{f}}$ and $\mathrm{b}_{\mathrm{f}}$, the linear form of the equation as shown below may be used to plot $\ln \left(\mathrm{q}_{\mathrm{e}}\right)$ against $\ln \left(\mathrm{C}_{\mathrm{e}}\right)$ as:

$$
\operatorname{Lnq_{e}}=\operatorname{Ln} K_{f}+b_{f} \operatorname{LnC} C_{e}
$$

\section{Redlich - Petertson isotherm}

Redlich and Peterson proposed an empirical three parameter equation which may be used to represent adsorption equilibrium over a wide concentration range of adsorbate. The adsorbate concentration at equilibrium condition can be computed as follows:

$q e=\frac{K_{R} C_{e}}{1+a_{R} C_{e}^{\beta}}$

Where, $\beta$ is a constant parameter and is normally less than unity. This equation reduces to a linear isotherm at low surface coverage, to the freundlich isotherm at high adsorbate concentration and to the Langmuir isotherm when $\beta=1$. However, the equation cannot be linearised for easy estimation of the isotherm parameter $K_{R}, a_{R}$ and $\beta$. The linearization of the expression gives the following relation:

$$
\frac{C_{e}}{q_{e}}=\frac{1}{K_{R}}+\frac{a_{R}}{K_{R}} C_{e}^{\beta}
$$

Plotting $\mathrm{C}_{\mathrm{e}} / \mathrm{q}_{\mathrm{e}}$ against $C_{e}^{\beta}$ yields a straight line with slope $=\frac{a_{R}}{K_{R}}$ and intercept $=\frac{1}{K_{R}}$. However, plotting of Eq. 7 is not applicable because of three unknown parameters contained within the equation. Therefore, a minimization procedure is adopted to maximize the correlation coefficient between the theoretical data for $\mathrm{q}_{\mathrm{e}}$ predicted from Eq. 7 and the corresponding experimental data. More often, the method used to determine isotherm parameters is the linear regression with transformed variables. The quality of the fit of the experimental data with the isotherm equation is assessed on the magnitude of the correlation coefficient for the regression. In other words, the isotherm giving the correlation coefficient closest to unity provides the best fit.

\section{Tempkin isotherm}

Tempkin and pyzhev are considered as the effect of some indirect adsorbate/adsorbate interaction on adsorption isotherms and suggested that because of interaction the heat of adsorption of all the molecules in the layer would decrease linearly with coverage. The amount of adsorbate can be given as below:

$q e=\left(\frac{R T}{b}\right) \ln A C_{e}$

Eq. 7 can be expressed in its linear form as:

$q_{e}=B \ln A+B \ln C_{e}$

with

$B=\frac{R T}{b}$

The adsorption data can be analyzed according to Eq. 9 and a plot of qe versus lnCe enables the determination of the isotherm constant, A and B. It would be worth noting that the constant $\mathrm{B}$ is related to heat of adsorption.

\section{Error functions}

In the present study, five different error functions were examined and in each case the respective error function across the liquid phase concentration range using the QBasic software. 
The sum of square of the average squares of the errors

Here, the error function minimized the fractional error distribution across the entire concentration range

$E R A V=\left[\frac{1}{p} \sum_{i=1}^{p}\left(q_{e, \text { calc }}-q_{e, \text { meas }}\right)^{2}\right]^{1 / 2}$

Where, $\mathrm{q}_{\mathrm{e}, \text { calc }}$ is the equilibrium capacity $(\mathrm{mg} / \mathrm{g})$ calculated from the applied model and $\mathrm{q}_{\mathrm{e} \text {, meas }}$ is the equilibrium capacity $(\mathrm{mg} / \mathrm{g})$ obtained from the experimental data. If data from the model are similar to the experimental data, ERAV will be a small number; if they are different, ERAV will be a large number (Khans et al., 1997).

\section{The sum of the squares of the errors}

This widely used error function has one major drawback. The function will result in the calculated isotherm parameters providing a better fit at the higher end of the liquid phase concentration range. This is because the magnitude of the errors and hence the square of the errors will increase as concentration increases.

$$
E R R S Q=\sum_{i=1}\left(q_{e, \text { calc }}-q_{e, \text { meas }}\right)_{i}^{2}
$$

\section{The hybrid fractional error function}

This error function was developed in order to improve the fit of the ERRSQ method at low concentration values. In this method, each ERRSQ value was divided by the experimental solid phase concentration $q$ value. In addition, a divisor was included as a term for the number of degrees of freedom for the system, the number of data points minus the number of parameters within the isotherm equation.

$$
H Y B R Y I D=\frac{100}{P-n} \sum_{i=1}^{p}\left[\frac{\left(q_{e, \text { meas }}-q_{e, \text { calc }}\right)^{2}}{q_{e, \text { meas }}}\right]
$$

\section{Marquardt's percent standard deviation}

This error function was similar to a geometric mean error distribution which was modified to allow for the number of degrees of freedom of the system.

$$
\begin{aligned}
& \left.M P S D=100\left(\sqrt{\left(\frac{1}{p-n} \sum_{i=1}^{p}\left[\frac{\left(q_{e, \text { meas }}-q_{e, \text { calc }}\right)^{2}}{q_{e, \text { meas }}}\right]\right)}\right)\right)_{(1)} \\
& \chi^{2}=\sum_{i=1}^{p}\left(\frac{\left(q_{e, \text { meas }}-q_{e, \text { calc }}\right)^{2}}{q_{e, \text { calc }}}\right)
\end{aligned}
$$

Chi-square analysis ( $(2)$

The advantage of using chi-square test is to compare all isotherms on the same abscissa and ordinate. The equivalent mathematical statement was:

If data from model were similar to the experimental data, $\chi 2$ would be a small number and vice versa the values of $\chi 2$ of each model were shown in Table 1.

\section{RESULTS AND DISCUSSION}

Table 1 presents the values of the parameters introduced by the Langmuir isotherm, i.e., $\mathrm{a}_{\mathrm{L}}$ and $\mathrm{k}_{\mathrm{L}}$, associated with the correlation coefficient obtained from least square fit of the model to the corresponding experimental data. Also, it can be seen from Table 1 that the type of objective function used to obtain the regressed values of the parameters was mentioned to be error functions. As mentioned earlier, the error functions can be given by Eqs. 11-15. The values of the parameters can be directly used to obtain the amount of adsorbat to be sorbed onto the expanded perlite studied in this work. As observed from Table 1 , the correlation of the Langmuir isotherm was performed with the sorption experimental data of different types of crude oil onto the expanded perlite.

Table 2 illustrates the values of the parameters introduced by the Freunlich isotherm, i.e., $\mathrm{K}_{\mathrm{F}}$ and $\mathrm{b}_{\mathrm{f}}$, associated with the correlation coefficient obtained from least square fit of the model to the corresponding experimental data. Moreover, it can be seen from Table 2 that the type of objective function used to obtain the regressed values of the parameters was mentioned to be error functions.

\section{Redlich - Petertson isotherm}

The Redlich-peterson isotherm plots for sorption of crude oils on expanded perlite are presented in Fig. 1. Again, examination of the plot shows that the Redlich-peterson isotherm accurately describes the sorption behaviors of crude oil on expanded perlite over the concentration ranges studied. The Redlichpeterson isotherm constants, $\mathrm{K}_{\mathrm{R}}, \mathrm{a}_{\mathrm{R}}, \beta$ and $\mathrm{R}^{2}$ and errors function are presented in Table 3 . Since the method used to derive the isotherm parameters maximizes the linear coefficient of determination, it is unsurprising that in this case, the Redlich-peterson isotherm exhibit extremely high $\mathrm{R}^{2}$ values indicating, superficially at least, that it produces a considerably better fit compared to the preceding two-parameter isotherms. This equation reduces to a linear isotherm 
Int. J. Environ. Sci. Tech., 7 (3), 591-598, Summer 2010

Table 1: Langmuir isotherm constants $\mathrm{a}_{\mathrm{L}}$ and $\mathrm{K}_{\mathrm{L}}$ and errors function

\begin{tabular}{|c|c|c|c|c|}
\hline Oil Type & $a_{L}$ & $\mathrm{~K}_{\mathrm{L}}$ & $\mathrm{R}^{2}$ & Chi-Square \\
\hline I. O. L & $6.584 * 10^{-}$ & 0.42311 & 0.9132 & $9.2314 * 10^{-1}$ \\
\hline M. As & $7.248 * 10-2$ & 0.4756 & 0.9356 & $1.152 * 10^{-1}$ \\
\hline Oil Type & ERAV & ERRSQ & HYBRID & MPSD \\
\hline I O.L & 2.3645 & 0.7860075 & 1.073953 & 10.36317 \\
\hline M. As & 2.5463 & 0.82314 & 1.15243 & 11.4567 \\
\hline
\end{tabular}

Table 2. Freundlich isotherm constants $\mathrm{K}_{\mathrm{f}}$ and $\mathrm{b}_{\mathrm{f}}$ and errors function

\begin{tabular}{|c|c|c|c|c|}
\hline Oil Type & $\mathrm{K}_{\mathrm{F}}$ & $b_{f}$ & $\mathrm{R}^{2}$ & Chi-Square \\
\hline I. O. L & 2.531 & 0.23278 & 0.989 & $5.8513 * 10^{-2}$ \\
\hline M. As & 2.7846 & 0.2506 & 0.988 & $6.54 * 10^{-2}$ \\
\hline Oil Type & ERAV & ERRSQ & HYBRID & MPSD \\
\hline I. O. L & 0.928562 & $1.081 * 10^{-2}$ & $6.5227 * 10^{-3}$ & 0.8078 \\
\hline M. As & 0.98251 & $1.15 * 10^{-2}$ & $8.754 * 10^{-3}$ & 0.9423 \\
\hline
\end{tabular}

Table 3: Redlich-Peterson isotherm constants $\mathrm{K}_{\mathrm{R}}, \mathrm{a}_{\mathrm{R}}, \beta, \mathrm{R}^{2}$ and errors function

\begin{tabular}{|c|c|c|c|c|c|}
\hline Oil Type & $\mathrm{K}_{\mathrm{R}}$ & $a_{R}$ & $\beta$ & $\mathrm{R}^{2}$ & Chi-Square \\
\hline I .O.L & 5.190622 & 1.90345 & 0.78 & 0.999 & $1.025 * 10^{-2}$ \\
\hline M. As. & 5.092 & 2.0452 & 0.79 & 0.999 & $4.32 * 10^{-2}$ \\
\hline Oil Type & ERAV & ERRSQ & HYBRID & MPSD & \\
\hline I .O.L & 0.1927 & $9.445^{*} 10^{-3}$ & $1.132 * 10^{-3}$ & 0.7254 & \\
\hline M. As. & 0.2841 & $7.458 * 10^{-3}$ & $7.674 * 10^{-3}$ & 0.9843 & \\
\hline
\end{tabular}

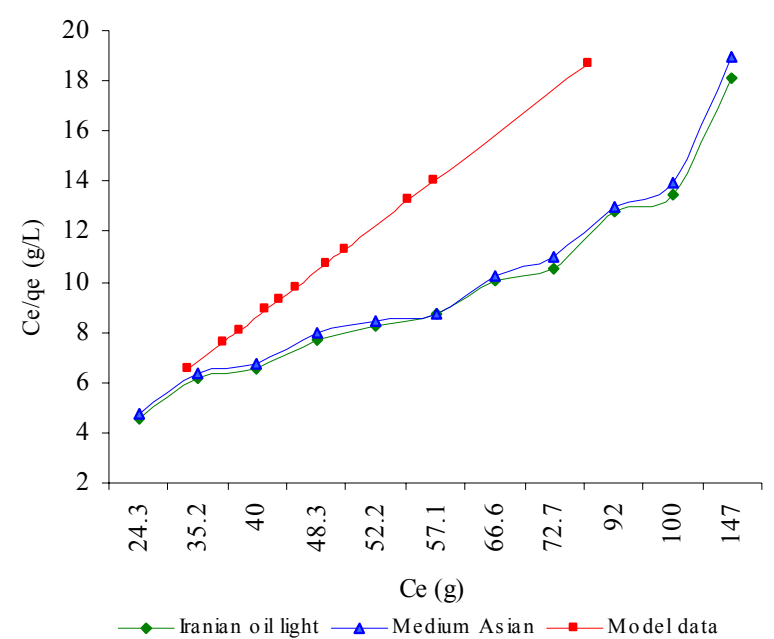

Fig. 1: Langmuir isotherm and model data

at low surface coverage, to the Freundlich isotherm at high adsorbate concentration and to the Langmuir isotherm when $\beta=1$.

\section{Tempkin isotherm}

The Tempkin isotherm plots for sorption of crude oils on expanded perlite are presented in Fig. 2. The Tempkin isotherm constants, $\mathrm{A}, \mathrm{B}, \mathrm{R}^{2}$ and errors function are presented in Table 4.
The different forms non- linear isotherms

The different Non-linear forms of Redlich-peterson, Freundlich, Langmuir and Tempkin isotherm plots and the experimental data for sorption of crude oils on expanded perlite are presented in Figs. 3 and 4. Therefore, drawing conclusion from the Redlichpeterson isotherm was best-fitting isotherm, followed by the Freundlich model for this sorption system.

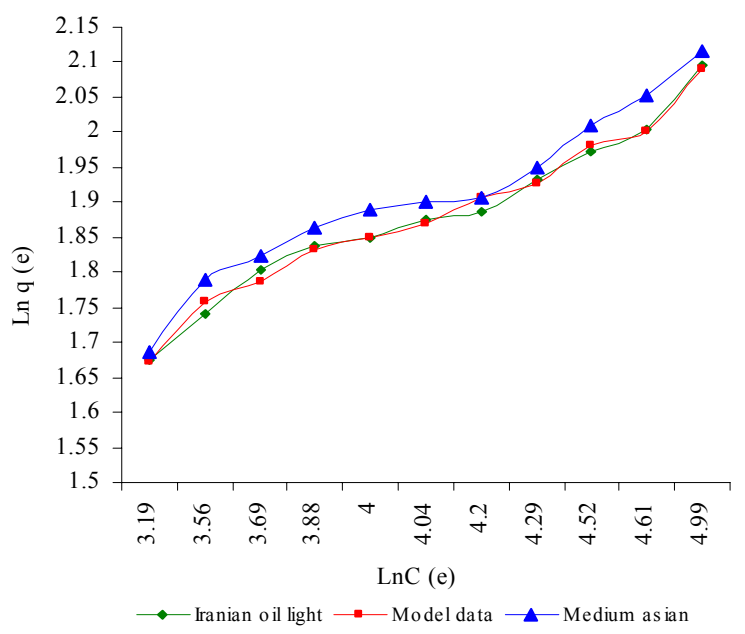

Fig. 2: Frundlich isotherm and model data 
Table 4: Tempkin isotherm constants $\mathrm{A}, \mathrm{B}, \mathrm{R}^{2}$ and errors function

\begin{tabular}{lrcrc}
\hline Oil Type & A & B & $\mathrm{R}^{2}$ & Chi-Square \\
\hline I.O.L & 12 & 0.6678 & 0.98 & $4.2664^{*} 10^{-2}$ \\
M .As & 14 & 0.7845 & 0.974 & $4.537 * 10^{-2}$ \\
Oil Type & ERAV & ERRSQ & HYBRID & MPSD \\
I.O.L & 0.3105 & $8.3224^{*} 10^{-2}$ & $1.410318 * 10^{-1}$ & 3.7554 \\
M.As & 0.98251 & $2.5^{*} 10^{-2}$ & $9.724 * 10^{-2}$ & 4.658 \\
\hline
\end{tabular}

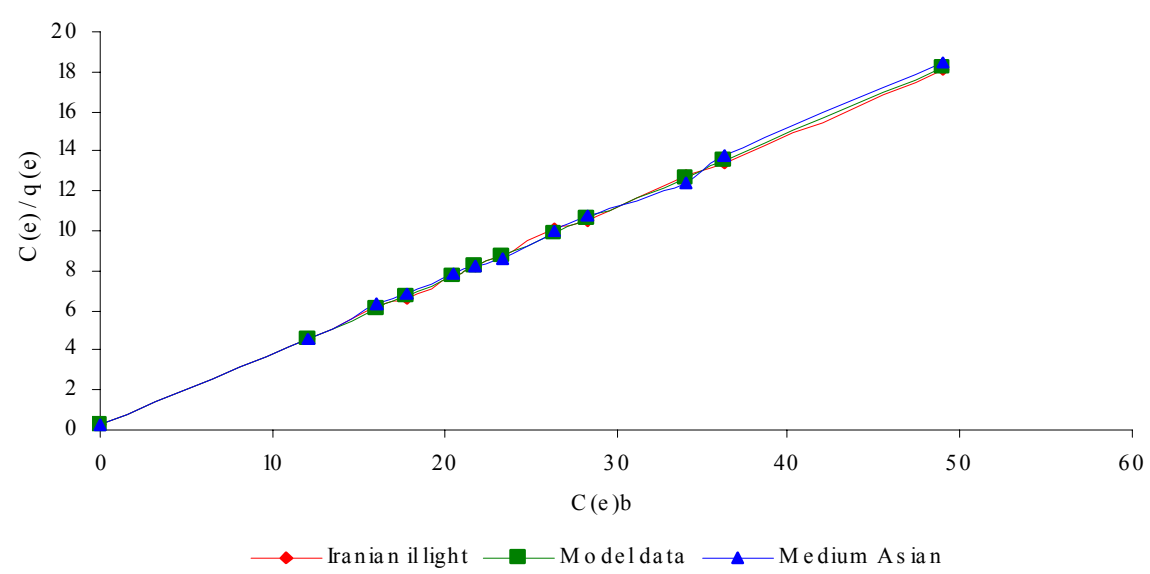

Fig. 3: Redlich- Peterson isotherm and model data

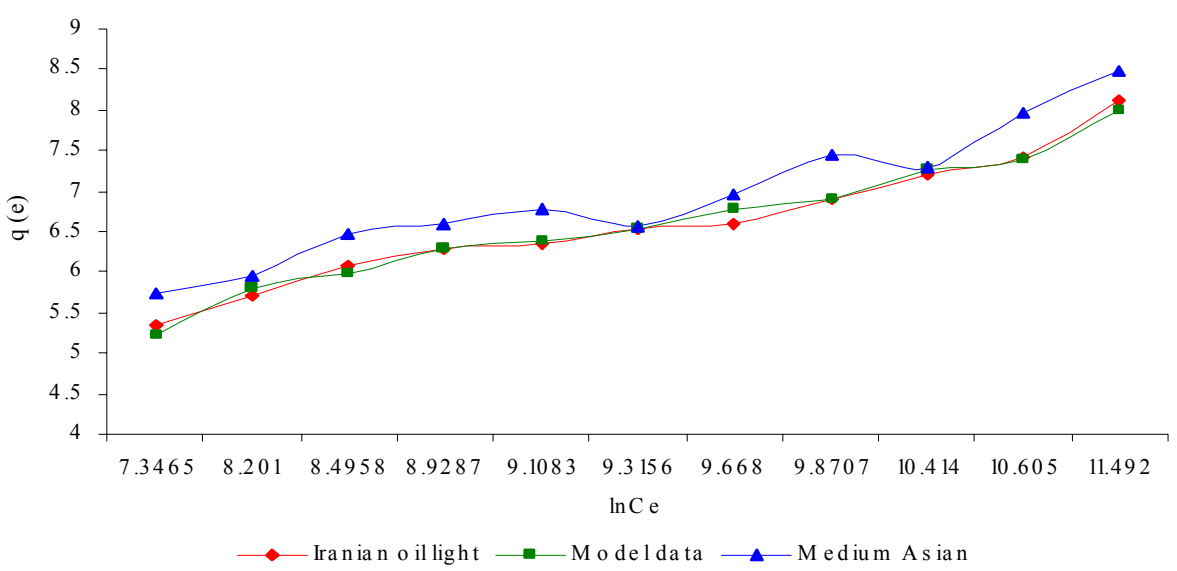

Fig. 4: Temkain isotherm and experimental data

\section{CONCLUSION}

The equilibrium adsorption of two-type crude oil by expanded perlite has been reported. The results revealed the potential of the expanded perlite is suitable to be a low-cost sorbent for clean-up crude oil. The equilibrium results have been modeled and evaluated using four different isotherms and five different error functions including a linear transform model. The results showed that the equilibrium data for all the crude oil-sorbent systems are fitted to the Redlich-Peterson and Freundlich isotherms model best. The linear transform model provided highest correlation coefficient for the case of the Redlich-Peterson isotherm $\left(\mathrm{R}^{2}=0.999\right)$. The $\mathrm{R}^{2}$ for 
Langmuir isotherm is 0.9132 troughs 0.93561 . Besides, the sum of square of the average squares of the errors (ERAV) equal 2.36451 for Langmuir isotherm. The Langmuir isotherm theory assumes monolayer coverage of adsorbate over a homogenous adsorbent surface. Using of the error functions for optimization showed that often the isotherms were generally better represented using the ERRSQ, HYBRID and Chi-Square errors function.

\section{Nomenclature}

$a_{\mathrm{L}:} \quad$ Langmuir isotherm constant $\left(\mathrm{dm}^{3} / \mathrm{mg}\right)$

$a_{\mathrm{R}}$ : Redlich-Peterson isotherm constant $\left(\mathrm{dm}^{3} / \mathrm{mg}\right)$

$A$ : Tempkin isotherm constant

$b$ : Tempkin isotherm energy constant $(\mathrm{J} / \mathrm{mol})$

$b_{\mathrm{F}}$ : Freundlich isotherm exponent

$B$ : Tempkin isotherm energy constant $\left(\mathrm{dm}^{3} / \mathrm{g}\right)$

$C_{0:}$ Initial liquid-phase concentration $\left(\mathrm{mg} / \mathrm{dm}^{3}\right)$

$C_{\text {e: }}$ Equilibrium liquid-phase concentration $\left(\mathrm{mg} / \mathrm{m}^{3}\right)$

ERRSQ: The sum of the squares of errors

HYBRID: The hybrid fractional error function

$K_{\mathrm{F}}:$ Freundlich isotherm constant $\left(\mathrm{dm}^{3} / \mathrm{g}\right)$

$K_{\mathrm{L}:}$ Langmuir constant $\left(\mathrm{dm}^{3} / \mathrm{g}\right)$

$K_{\mathrm{R}:}$ Redlich-Peterson isotherm constant $\left(\mathrm{dm}^{3} / \mathrm{g}\right)$

MPSD: Marquardt's percent standard deviation

$n$ : Number of isotherm parameters

$p$ : Number of data points

$q_{\mathrm{e}}$ : Equilibrium solid-phase concentration ( $\mathrm{mg} / \mathrm{g}$ )

$Q_{\text {o: }}$ Monolayer capacity of Langmuir equation (mg/g)

$q_{\text {e, calc: }}$ Calculated dye equilibrium solid phase concentration $(\mathrm{mg} / \mathrm{g})$

$q_{\text {e, meas }}:$ Measured dye equilibrium solid phase concentration $(\mathrm{mg} / \mathrm{g})$

$R:$ Gas constant $(\mathrm{J} \mathrm{mol} / \mathrm{K})$

$T$ : Temperature $(\mathrm{K})$

$\beta$ : Exponent in Redlich-Peterson isotherm

\section{REFERENCES}

Abdel-Ghani, N. T.; Hegazy, A. K.; El-Chaghaby, G. A., (2009). Typha domingensis leaf powder for decontamination of aluminium, iron, zinc and lead: Biosorption kinetics and equilibrium modeling. Int. J. Environ. Sci. Tech., 6 (2), 243 248 (6 pages).

Acemioglu, B., (2005)., Batch kinetic study of sorption of methylene blue by perlite. Chem. Eng. J. 106 (1), 73-81 (8 pages).

Adams, R. H.; Guzmán, O. F. J.; Zavala Cruz, J., (2008). Water repellency in oil contaminated sandy and clayey soils. Int. J. Environ. Sci. Tech., 5 (4), 445-454 (10 pages).

Al-Duri, B.; McKay, G., (1988). Basic dye adsorption on carbon using a solid phase diffusion model. Chem. Eng. J.
38 (1), 23-31 (9 pages).

Allen, J.; Gan, Q.; Matthews, R.; Johnson, P. A., (2003). Comparison of optimized isotherm models for basic dye adsorption by kudzu. Bioresour. Tech., 88 (2), 143-152 (10 pages).

Bastani, D.; Safekordi, A. A.; Alihosseini, A.; Taghikhani, V., (2006). Study of oil sorption by expanded perlite at 298.15 K. Separat. Purificat. Tech., 52 (2), 295-300 (6 pages).

Chen, D. Z.; Zhang, J. X.; Chen, J. M., (2010). Adsorption of methyl tert-butyl ether using granular activated carbon: Equilibrium and kinetic analysis. Int. J. Environ. Sci. Tech., 7 (2), 235-242 (8 pages).

Dogan, M.; Alkan, M.; Onganer, Y., (2000). Adsorption of methylene blue from aqueous solution onto perlite. Water Air Soil Pollut., 120 (3-4), 229-248 (20 pages).

Freundlich, H., (1906). Adsorption in solution. Phys. Chem., 57, 384-470 (86 pages).

Ghalambor. A., (1999). Composting technology for practical and safe remediation of oil spill residuals. Technical report series. 98-103.

Gueu, S.; Yao. B.; Adouby, K.; Ado, G., (2007). Kinetics and thermodynamics study of lead adsorption on to activated carbons from coconut and seed hull of the palm tree. Int. J. Environ. Sci. Tech., 4 (1), 11-17 (7 pages).

Husseien, M.; Amer, A. A.; Sawsan, I. I., (2008). Oil spill sorption using carbonized pith bagasse: Trial for practical application. Int. J. Environ. Sci. Tech., 5 (2), 233-242 (10 pages).

Ingaki, M.; Toyada, M.; Iwashita, N.; Nishi, Y., (2001). Exfoliated graphite for spilled heavy oil recovery. Carbon Sci., 2: 1-8 (8 pages).

Kawahara, A.; Inagaki, M.; Konno, H., (2002). Sorption and recovery of heavy oils using carbonized fir fibers and recycling. Carbon. 40 (1), 105-111 (7 pages).

Khans, A. R.; Al-Bahri, T. A.; Al-Haddad, A., (1997). Adsorption of phenol based organic pollutants on activated carbon from multicomponent dilute aqueous solutions. Water Res., 31 (8), 2101-2112 (12 pages).

Langmuir, I., (1918). Adsorption of gases on plane surfaces of glass, mica and platinum. J. Am. Chem. Soc., 40 (9), 1361-1403 (42 pages).

Louis, S.; Pang, K., Simon, C.; Robinson, G.; Quezada, A., (1998). A study of the gross composition of oil-bearing fluid inclusions using high performance liquid chromatography. Org. Geochem. J., 29 (5-7), 1149-1161 (13 pages).

Mahvi, A. H., (2008). Application of agricultural fibers in pollution removal from aqueous solution. Int. J. Environ. Sci. Tech., 5 (2), 275-285 (11 pages).

Malik, P. K., (2004). Dye removal from wastewater using activated carbon developed from sawdust: Adsorption equilibrium and kinetics. J. Hazard. Mater., 113 (1-3), 81-88 (8 pages).

Marquardt, D. W., (1963). An algorithm for least squares estimation of non-linear parameters. Soc. Ind. Appl. Maths. J., 11 (2), $431-441$ (11 pages).

McKay, G., Ho, Y. S., (1998). Sorption of dye from aqueous solution by peat. Chem. Eng. J., 70 (2), 115-124 (10 pages).

Moon, H.; Lee, W. K., (1983). Intraparticle diffusion in liquid phase adsorption of phenols with activated carbon 
in a finite batch absorber. J. Coll. Interf. Sci. 96 (1), 四62-

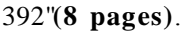

Nameni, M.; Alavi Moghadam, M. R.; Arami, M., (2008). Adsorption of hexavalent chromium from aqueous solutions by wheat bran. Int. J. Environ. Sci. Tech., 5 (2), 161-168 (8 pages).

Pandey, P. K., Sharma, S. K., Sambi, S. S., (2010). Kinetics and equilibrium study of chromium adsorption on zeolite NaX. Int. J. Environ. Sci. Tech., 7 (2), 395-404 (10 pages). Polatli, M.; Erdinc, M.; Erdinc, E.; Okayay, E., (2001). Perlite exposure and 4-years change in lung function. Environ. Res. Sec., 86 (3), 238-243 (6 pages).

Redlich, O.; Peterson, D. L., (1959). A useful adsorption isotherm. J. Phys. Chem. 63 (6), 1024-1026 (3 pages).

Riazi, M. R.; Al-Enezi, G. A., (1999). Modeling of the rate of oil spill disappearance from seawater for Kuwaiti crude and its products. Chem. Eng. J., 73 (2), 161-172 (12 pages).
Sylwia, K. W.; Jakub, N.; Edyta, W.; Jan, H.; Jan, D. M., (2003). Surface properties of barley straw. Coll. Surfac., 29 (2-3), 131-142 (12 pages).

Tempkin, M. J.; Pyzhev, V., (1940) Kinetics of ammonia synthesis on promted iron catalysts. Acta Phusiocim URSS., $12,217-222$ (6 pages).

Wu, F. C.; Tseng, R. L.; Juang, R. S., (2001). Kinetic modeling of liquid-phase adsorption of reactive dyes and metal ions on chitosan. Water Res., 35 (3), 613-618 (6 pages).

Yoko, N.; Norio, I.; Yoshiro, S.; Michio, I., (2002) Sorption kinetics of heavy oil into porous carbons. Water Res., 36 (20), 5029-5036 (8 pages).

Yuh, H. S.; Tachiu, W.; Wang, C. C., (2005). Regression analysis for the sorption isotherms of basic dyes on sugarcane dust. Bioresour. Tech., 96 (11), 1258-1291 (34 pages).

\section{AUTHOR (S) BIOSKETCHES}

Alihosseini, A., Assistant Professor, Department of Chemistry, Islamic Azad University Ilam Branch, Ilam, Iran.

Email: afsharalihosseini@yahoo.com

Taghikhani, V., Full Professor, Department of Chemical and petroleum Engineering, Sharif University of Technology, Tehran, Iran.

Email: taghikhani@sharif.edu

Safekordi, A. A., Full Professor, Department of Chemical and petroleum Engineering, Sharif University of Technology, Tehran, Iran. Email: safekordi@sharif.edu

Bastani, D., Full Professor, Department of Chemical and petroleum Engineering, Sharif University of Technology, Tehran, Iran. Email: bastani@sharif.edu

How to cite this article: (Harvard style)

Alihosseini, A.; Taghikhani, V.; Safekordi, A. A.; Bastani, D., (2010). Equilibrium sorption of crude oil by expanded perlite using different adsorption isotherms at 298.15 k. Int. J. Environ. Sci. Tech., 7 (3), $591-598$. 